\title{
Well-being and mental health of healthcare workers before, during, and after COVID-19
}

\author{
Emmeline Lagunes Cordoba ${ }^{1,2}$
}

Camden and Islington NHS Foun-
dation Trust, UK.
2 King's College London, Institute of
Psychiatry, Psychology and Neuro-
science, UK.
Correspondence:
Emmeline Lagunes Cordoba
Camden and Islington NHS
Foundation Trust
3 Daleham Gardens,
NW3 5BY, London, UK.
Phone: (+44) O2O 3317-6333
Email: emmeline.lagunescordoba@
candi.nhs.uk
Citation:
Lagunes Cordoba, E. (2021). We-
II-being and mental health of health-
care workers before, during, and af-
ter COVID-19. Salud Mental, 44(5),
211 -2 14 .
Dol: 10.17711 /SM.0185-3325.2021.027
The World Health Organization states that people's mental health is as essential and important to our well-being as is our physical health (World Health Organization [WHO], 2021). This is because, when we feel mentally well, we can not only be productive and contribute to our communities, but we can also enjoy our free time (WHO, 2021), and arguably enjoy our lives. The recognition of this intricated relationship has led to multiple studies focused on identifying those factors impacting people's well-being and mental health. For example, alcohol consumption and obesity have been associated with poor mental health and quality of life (Rehm et al., 2009; Stranges, Savaraweera, Taggart, Kandala, \& Stewart-Brown, 2014), while physical activity, adequate sleep, and consumption of fruits and vegetables have been associated with better health and well-being (Stranges et al., 2014; Franco et al., 2012). As well as having good social support and socioeconomic stability (Soldevila Domenech et al., 2021; Stewart-Brown, Samaraweera, Taggart, Kandala, \& Stranges, 2015).

\section{PAST}

Although most studies have focused on the general population, attention has also been drawn to healthcare staff, as they are at a higher risk of developing burnout and mental health problems compared with workers in other fields (Shanafelt et al., 2012; Mata et al., 2015). The high prevalence of burnout and mental health problems in healthcare workers has been mainly associated with work-related factors, including: excessive workload, long-working hours, administrative burden, work-home conflicts, difficulty integrating professional and personal life, lack of support from colleagues and superiors, loss of autonomy and poor leadership. However, other individual factors, such as female sex, young age, having a child $<21$ years, and having a partner who is not a healthcare worker, have also been identified (West, Dyrbie, \& Shanafelt, 2018; Dyrbye et al., 2017; Patel, Bachu, Adikey, Malik, \& Shah, 2018).

Burnout has been associated with substance abuse, poor self-care, emotional exhaustion, reduced motivation, depression, suicidal ideation, and even motor vehicle crashes in health care staff. The impact of burnout is also extended to patient care and the whole healthcare system, as burnout has been associated with lower care quality, increased medical errors and patient mortality, longer recovery times, lower patient satisfaction, job dissatisfaction, reduced productivity, and increased costs (West et al., 2018; Patel et al., 2018).

To address burnout in healthcare staff, different strategies have been proposed. From the organisational perspective, proposed solutions include: fair productivity targets and distribution of job roles; duty hour limits; respect for non-working hours; support of flexible work; optimised electronic records; avoidance of task redundancy; physician engagement in leadership and management; shared decision-making; promotion of shared core values; opportunities for professional development; and training and awareness about burnout (West et al., 2018; Moss, Good, Gozal, Kleinpell, \& Sessler, 2016). Regarding individual strategies, these include: undertaking part-time jobs; taking informed practice choices; ef- 
ficiency and skills training; prioritising tasks and delegating work appropriately; reflection of life priorities; attention to self-care; stress management and resilience training; adoption of positive coping strategies, including mindfulness; and engagement in group activities focused on sharing and reflecting on work experiences (West et al., 2018; Moss et al., 2016). Understandably, adequate rest, exercise, meditation, adoption of hobbies, social support, and higher self-esteem have also been associated with reduced burnout and higher quality of life in healthcare workers (Moss et al., 2016; Iqbal, Iqbal, Khan, Saad, \& Kassab, 2020).

\section{PRESENT}

Despite past efforts to improve the well-being of healthcare professionals, in practice, few interventions have been implemented. However, after the onset of the COVID-19 pandemic, which caused most healthcare services to become overwhelmed, the well-being of healthcare workers gained important attention, probably due to the numerous reports of staff feeling psychically and emotionally drained. Studies focused on these professionals, showed an increment of mental health problems, with results suggesting that one in five healthcare workers had experienced insomnia, depression, anxiety, and even post-traumatic stress disorder (PTSD) during the pandemic (Pappa et al., 2020; Li, Scherer, Felix, \& Kuper, 2021). These staggering results have been attributed not only to the increased workload, the unexpected role changes (many workers were redeployed) and the lack of resources (including protective equipment), but also to the complexity of the virus, the changing clinical guidelines, and the constant exposure to trauma-related stress and death (Søvold et al., 2021). All of these elements could also contribute to staff developing "moral injury".

The term "moral injury", originated within the military, is defined as the psychological distress experienced when people face demands for which they feel unprepared, and when their actions, or lack of them, contradict someone's moral values or ethical codes (Greenberg, Docherty, Gnanapragasam, \& Wessely, 2020b; Tracy et al., 2020). This can cause people to feel guilty or ashamed, and contribute to the development of mental health problems, including depression and PTSD (Tracy et al., 2020). Although moral injury and PTSD are likely to happen when people face traumatic events, some people might also experience post-traumatic "growth", a term that describes the boost of self-esteem and psychological resilience one experiences after facing a challenging situation (Greenberg et al., 2020b). Although it might be hard to anticipate who would develop injury or growth, healthcare leaders can play an important role in the prevention, identification and management of negative effects secondary to work-related trauma.
Some of the interventions that have been proposed to ensure the psychological well-being of healthcare workers during periods of intense stress, include: providing up-todate information; recognising people's contribution, mainly during the challenging period; giving thanks (written and verbally); and reinforcing bonds between colleagues and supervisors (Greenberg \& Tracy, 2020; Greenberg et al., 2020a). As people struggling with mental health symptoms often avoid seeking help, interventions also include training supervisors in identifying signs of distress, having supportive conversations focused on mental health, and helping individuals to develop recovery plans (Greenberg \& Tracy, 2020; Greenberg et al., 2020b). Finally, although is important not to medicalise normal responses to trauma, it is advised that leaders and supervisors ensure healthcare staff can promptly access mental health services, preferably, within their same work premises. This with the aim of establishing if people can return to work, with some adjustments to their roles, or need a formal assessment to avoid distress escalating into a crisis (Tracy et al., 2020).

\section{FUTURE}

Although we are still far from declaring the battle against COVID-19 won, the pandemic has helped healthcare workers gain more recognition and support, not only from organisation leaders, but also from the general population, with many recognising the need of implementing long-term strategies to protect the well-being and mental health of healthcare staff.

From the organisational point of view, researchers and medical organisations have proposed the following recommendations: Prioritising the well-being and mental health of staff; encouraging help-seeking; ensuring there is available, accessible and equal help for all healthcare workers in distress; taking mental well-being seriously; ensuring adequate staffing levels and fair pay for workers; implementing a simple process for taking sickness leave; combating stigmatisation and promoting open dialogues about mental health; allowing staff to take time off or work flexibly; and encouraging healthcare workers to engage in leadership and the shaping of their roles (Søvold et al., 2021; Brtish Medical Association, 2020). Although some of these solutions have been proposed before, there has been a shift in the way staff's well-being is now regarded as a priority and a responsibility of healthcare organisations, and not only as an element individuals are solely accountable.

Despite this apparent shift, it is hard to foresee if these changes will be implemented, as it is likely that healthcare organisations will continue struggling meeting the ever-growing health needs of most populations. Additionally, most recommendations have come from researchers and or- 
ganisations from high-income countries, where healthcare systems might not face the same pressures and lack of resources like those from low and middle-income countries (LAMIC). During the pandemic, healthcare services in some LAMIC have come to the verge of collapse, not only by not been able to meet the overwhelming demands (Davies \& Furneaux, 2021), but also by not being able to guarantee even the physical safety of their staff. To this date, there are some countries in Latin America, where some doctors and healthcare staff are still not vaccinated or getting adequate support and equipment (Camhaji \& Moran Breña, 2021). Also, in some LAMIC, people have threatened and physical attacked healthcare workers and healthcare facilities (McKay, Heisler, Mishori, Catton, \& Kloiber, 2020). So, it might be naïve to think that in these countries the well-being and mental health of healthcare staff will be prioritised.

\section{NOW}

Regardless of whether healthcare workers are supported or not, it is adamant that they prioritise their own health and well-being, as it is unlikely things will improve if they do not act. Many people think that to be a doctor or to work in healthcare is a vocation that requires people to sacrifice their own well-being, a view that can cause staff to feel guilty if they prioritise their needs. However, during a time when kindness and compassion have become central aspects of medical care, it is paradoxical that healthcare workers are expected to be kind and compassionate with everyone else but themselves.

"Treat others the way you want to be treated" says the famous Golden Rule. However, I strongly believe we need to start with: "Treat yourself the way you want others to treat you". We need to recognise that prioritising our well-being, is not only something good, but also needed for us to be able to provide to patents the care we so highly regard. We also need to recognise that by being kind and compassionate towards ourselves, we are also taking care of the people we love. Someone is not a bad doctor for leaving work on time to be able to have dinner with their family; he or she is only being kind and loving with themselves and the people they love. No one should be made feel guilty for doing this.

With twenty-one years into the twenty-first century, now it is a good time to recognise healthcare workers are not heroes, nor martyrs, just people equally deserving the same care and compassion they give to the patients they treat. With this in mind, I propose the following recommendations that anyone can implement immediately: take care of yourself; eat healthy; sleep well; be indulgent but limit your alcohol consumption; get active; always be on time, but do not stay longer, work never ends, no matter how long you stay; set boundaries, say no to unfeasible requests; maintain your social connections and hobbies, this is essential for our well-being; reward yourself, we need to enjoy the product of our work; recognise and praise your effort, what you do matters; support and be kind to others, we are part of the same team; and ask for help, we all need it. Finally, be kind and treat yourself the same way you would treat the people you love, you would never put them under the same strains you put yourself. The well-being and mental health of healthcare workers matter, so let us begin with prioritising yours.

\section{REFERENCES}

Brtish Medical Association. (2020). The mental health and wellbeing of the medical workforce - now and beyond COVID-19. BMA. Retrieved from https://www. bma.org.uk/media/2475/bma-covid-19-and-nhs-staff-mental-health-wellbeingreport-may-2020.pdf

Camhaji, E., \& Moran Breña, C. (2021, April 03). Los médicos privados de México alzan la voz: "El Gobierno nos ha dado la espalda". México: El País. Retrieved from https:/elpais.com/mexico/2021-04-03/los-medicos-privados-de-mexicoalzan-la-voz-el-gobierno-nos-ha-dado-la-espalda.html (Access date July 23, 2021)

Davies, M., \& Furneaux, R. (2021, May 25). Oxygen shortages threaten 'total collapse' of dozens of health systems. The Guardian. Retrieved from https:// www.theguardian.com/global-development/2021/may/25/oxygen-shortagesthreaten-total-collapse-of-dozens-of-health-systems (Access date July 23, 2021)

Dyrbye, L. N., Shanafelt, T. D., Sinsky, C. A., Cipriano, P. F., Bhatt, J., Ommaya, A., ... Meyers, D. (2017). Burnout Among Health Care Professionals: A Call to Explore and Address This Underrecognized Threat to Safe, High-Quality Care. NAM Perspectives. doi: 10.31478/201707b

Franco, O. H., Wong, Y. L., Kandala, N.-B., Ferrie, J. E., Dorn, J. M., Kivimäki, M., \& Stranges, S. (2012). Cross-cultural comparison of correlates of quality of life and health status: the Whitehall II Study (UK) and the Western New York Health Study (US). Eur J Epidemiol, 27(4), 255-265. doi: 10.1007/s10654-012-9664-Z

Greenberg, N., \& Tracy, D. (2020). What healthcare leaders need to do to protect the psychological well-being of frontline staff in the COVID-19 pandemic. BMJ Leader, 4(3), 101-102. doi: 10.1136/leader-2020-000273

Greenberg, N., Brooks, S., Wessely, S., \& Tracy, D. (2020a). How might the NHS protect the mental health of health-care workers after the COVID-19 crisis? The Lancet Psychiatry, 7(9), 733-734. doi: 10.1016/S2215-0366(20)30224-8

Greenberg, N., Docherty, M., Gnanapragasam, S., \& Wessely, S. (2020b). Managing mental health challenges faced by healthcare workers during covid-19 pandemic. $B M J, 368, \mathrm{~m} 1211$. doi: 10.1136/bmj.m1211

Iqbal, M. S., Iqbal, M. Z., Khan, S. D., Saad, E. M., \& Kassab, Y. W. (2020). Evaluation of health-related quality of life among healthcare professionals-A cross-sectional study findings. Medical Science, 24(106), 4471-4476. Retrieved from https:// www.discoveryjournals.org/medicalscience/current_issue/v24/n106/A81.pdf

Li, Y., Scherer, N., Felix, L., \& Kuper, H. (2021). Prevalence of depression, anxiety and post-traumatic stress disorder in health care workers during the COVID-19 pandemic: A systematic review and meta-analysis. PLOS ONE, 16(3), e0246454. doi: 10.1371/journal.pone.0246454

Mata, D. A., Ramos, M. A., Bansal, N., Khan, R., Guille, C., Di Angelantonio, E., $\&$ Sen, S. (2015). Prevalence of Depression and Depressive Symptoms Among Resident Physicians, A Systematic Review and Meta-analysis. JAMA, 314(22), 2373-2383. doi: 10.1001/jama.2015.15845

McKay, D., Heisler, M., Mishori, R., Catton, H., \& Kloiber, O. (2020). Attacks against health-care personnel must stop, especially as the world fights COVID-19. The Lancet, 395(10239), 1743-1745. doi: 10.1016/S0140-6736(20)31191-0

Moss, M., Good, V. S., Gozal, D., Kleinpell, R., \& Sessler, C. N. (2016). Collaborative Statement-Burnout Syndrome in Critical Care Health-care Professionals: A Call for Action. Chest, 150(1), 17-26. doi: 10.1016/j.chest.2016.02.649

Pappa, S., Ntella, V., Giannakas, T., Giannakoulis, V. G., Papoutsi, E., \& Katsaounou, P. (2020). Prevalence of depression, anxiety, and insomnia among healthcare workers during the COVID-19 pandemic: A systematic review and meta- 
analysis. Brain, Behavior, and Immunity, 88, 901-907. doi: 10.1016/j. bbi.2020.05.026

Patel, R. S., Bachu, R., Adikey, A., Malik, M., \& Shah, M. (2018). Factors Related to Physician Burnout and Its Consequences: A Review. Bahavioural Science, 8(11). doi: 10.3390/bs8110098

Rehm, J., Mathers, C., Popova, S., Thavorncharoensap, M., Teerawattananon, Y., \& Patra, J. (2009). Global burden of disease and injury and economic cost attributable to alcohol use and alcohol-use disorders. The Lancet, 373(9682), 2223-2233. doi: 10.1016/S0140-6736(09)60746-7

Shanafelt, T. D., Boone, S., Tan, L., Dyrbye, L. N., Sotile, W., \& Oreskovich, M. R. (2012). Burnout and Satisfaction With Work-Life Balance Among US Physicians Relative to the General US Population. Arch Intern Med, 172(18), 1377-1385. doi: 10.1001/archinternmed.2012.3199

Soldevila Domenech, N., Forero, C., Alayo, I., Capella, J., Colom, J., Malmusi, D., ... Alonso, J. (2021). Mental well-being of the general population: direct and indirect effects of socioeconomic, relational and health factors. Qual Life Res, 30(8), 2171-2185. doi: 10.1007/s11136-021-02813-5

Søvold, L. E., Naslund, J. A., Kousoulis, A. A., Saxena, S., Qoronfleh, M. W., Glober, C., \& Münter, L. (2021). Prioritizing the Mental Health and Well-Being of Healthcare Workers: An Urgent Global Public Health Priority. Front Public Health, 9, 679397 doi: 10.3389/fpubh.2021.679397
Stewart-Brown, S., Samaraweera, P. C., Taggart, F., Kandala, N.-B., \& Stranges, S. (2015). Socioeconomic gradients and mental health: implications for public health. British Journal of Psychiatry, 206(6), 461-465. doi: 10.1192/bjp. bp. 114.147280

Stranges, S., Savaraweera, P. C., Taggart, F., Kandala , N.-B., \& Stewart-Brown, S. (2014). Major health-related behaviours and mental well-being in the general population: the Health Survey for England. BMJ Open, 4(9):e005878. doi: 10.1136/bmjopen-2014-005878

Tracy, D. K., Tarn, M., Eldridge, R., Cooke, J., Calder, J., \& Greenberg, N. (2020). What should be done to support the mental health of healthcare staff treating COVID-19 patients? The British Journal of Psychiatry, 217(4), 537-539. doi: 10.1192/bjp.2020.109

West, C. P., Dyrbie, L. N., \& Shanafelt, T. D. (2018). Physician burnout: contributors, consequences and solutions. J Intern Med, 283(6), 516-529. doi: 10.1111/ joim. 12752

World Health Organization. (2021). Mental well-being: resources for the public. Retrieved from https://www.who.int/news-room/feature-stories/mental-wellbeing-resources-for-the-public (Access date July 20, 2021) 